\title{
QUALITY ASSESSMENT FOR A COMPANY
}

\author{
Nicolae Dobrițoiu, dobritoiun_2001@yahoo.com \\ Universitatea din Petroşani
}

\begin{abstract}
The competitive environment of modern society has laid down a set of very restrictive rules for all the firms that rise to the challenge; one of the most important problems that arises is the average quality met by a firm.

The great demand of products and services that satisfy the demands forces firms to continuously improve the quality of all their activities in order to meet all the demands of the clients.

If non-quality appears - during a certain activity - the quality of the services or products offered by the firm may seriously compromise the reputation of the firm.

In order to avoid this phenomenon, it is compulsory to bring into practice, besides that the quality systems, a new method to determine the level of quality achieved, from the employee, the staff, the organizational subdivision and the firm's point of view.
\end{abstract}

\section{The Concept of Quality}

A given product can be technically perfect, it can be manufactured out of adequate materials and through an effective technological process and yet, it may be rejected by target customers proving to be unsuccessful on the market.

This means that technologists opinion concerning the concept of quality does not always match that of consumers. Products that meet the standards are not necessarily successful from a commercial point of view. Well, then what is the use of quality if, despite its complying with standards, the product is not accepted thus being unable to yield the profit needed by the company to hold out? Should the concept of quality be revised and then redefined?

The idea of quality viewed only as adjustment to standards used to be of use within a background where the ratio demand / capacity was higher than the unit. This situation held through in the fifties and sixties.

But as the balance between these two terms became more obvious, selling also became more difficult, others strategies being necessary. Therefore marketing underwent an important development as a means of selling products facing greater competition (in the seventies).

At present, one can find saturated markets and ever more demanding consumers. It is already no longer enough to manufacture well. What is needed is to facilitate what consumers do expect, to adjust products to their needs, demands and expectations.

For this reason, it is necessary to devise a new conception concerning quality which is expected to take into account the target customer for the product or service and even more than that, to place the customer on the central axis of organizational activities. In order to best point out the concept of quality several definitons that go beyond the classical meaning of quality will be introduced further on.

- Predictable degree of uniformity at low cost, adequate to market needs (Deming).

- Designing, producing or providing goods or services that are as economically useful as possible as well as satisfactory to the beneficiary (Ishikawa).

- Quality: the extent to which a body of intrinsic characteristics (distinctive feature) meets the demands (need or expectation which is declared, generally implicit or compulsory), SR EN ISO 9000, February 2001. 
- "Extension through which a product or service fulfils a customer's specifications and is in compliance with its use". (U.S.A. Administration and Budget Department, 1988).

In the foregoing definitions, it can be noticed that reference to customer and to meeting his needs is a common element. If a choice were to be made, that would probably be Juran's definition (1993) :

"Quality is the body of characteristics of a product that meet the demands of customers and, consequently, make the product be satisfactory."

In conclusion, quality can be said to possess a dynamic in space, time and in the customer's level of education.

\section{Overall Quality}

Quality consists in bringing forth products or services that are satisfactory to the customer; consequently, one has to incorporate into it all the activities through which this satisfaction is received, irrespective of the place or type of company where the process is taking place.

This implies ensuring: the quality of products and services; the quality of resources; the quality of processes; the quality of both technical and human resources; the quality of administrative activities.

This conception comprising all of the organization and all of the activities is called overall quality. However, overall quality is not only a way of thinking but mainly a body of principles and methods aiming at satisfying the customer at the lowest cost. In order to fully understand overall quality mention must be made of a body of fundamental concepts.

Overall quality implies:

- Orienting the organization towards the needs of the customer. Meeting demands is the main issue. With this objective in mind, the unit is expected to focus on important processes which bring added value and make the achievement of this aim possible.

- The broadening of the concept of customer. The organization can be conceived as a system integrating providers and customers. Applying quality also means meeting the needs of the inside customer.

- Holding the leading position as far as prices are concerned. Quality is costly but nonquality is even more costly. If attention is to be focused on the needs and expectations of the customer, they will be better complied, with on condition that costs transfered to customer are lesser.

This cut in costs ensures competition on the market with genuine chances of success. It is therefore necessary for the costs of non-quality to be quantified.

- Prevention-based management. The underlying idea is that of doing things well from the first time and each and every time. It is better than in the case of the classical operations of detection and correction. The need to resort to control is reduced thus minimizing costs. This is the meaning Crosby gave to the phrase zero-faults.

- Improvement of the human factor. Quality is not to be controlled, it is achieved by the people belonging to the organization concerned, by all of them without exception. Therefore, the establishment of a management of human resources is necessary, starting with motivation for quality and participation.

- Continuous improvement. Quality is to be conceived as being a horizon rather than a goal. Overall quality cannot be achieved, instead, one is in pursuit of a horizon which keeps on broadening as one goes further on. This implies the idea of the continuous improvement of quality. It is always possible for products and services to be of higher quality and better adjusted to the needs and expectations of the customer which, on the other hand are dynamic. 


\section{Quality Representation}

Companies producing and providing products or services have as beneficiaries segments of population whitin a certain geographical area such as: age groups, professional groups, groups of population of certain level of education, political groups, social groups, etc.

If a company is to work and develop, it must, first and foremost, produce and provide products or services demanded by society. In other words, services must meet, to a high degree the needs, requirements and expectations of the population.

The existence of a fraction of inadequate products and services produced within a certain period of time and the possibility of taking a wrong decision concerning the quality of the products or services provided require the fixing of the following quality indicators:

1. Average quality after control $(A O Q)$ - is an indicator of the efficiency of a certain plan of control and it represents the average quality of the products and services provided after the control of a certain number of batches.

Within the sequence of control operations, apart from the accepted batches there will be rejected batches which will be checked up wholly and the inadequate products and services will be corrected.

If the sample, in the case of the accepted batch, has been reintroduced into the accepted batch without inadequate products or services being corrected, the average quality after control will be:

$$
A O Q=P \cdot P_{a}+0\left(1-P_{a}\right)=P \cdot P_{a}
$$

If, however, the sample is "filtered" out of the inadequate products or services before its being returned to the batch after the control operation then the indicator is determined as follows:

$$
A O Q=P \cdot P_{a}\left(1-\frac{n}{N}\right)
$$

Both the beneficiary and the provider are interested in knowing the $A O Q$ indicator; the former is interested in benefiting from batches of services of an average quality after control corresponding to his flow of achievement of services while the latter is interested in having an average quality after control very much like the quality of the batches he presented on the taking of delivery to avoid having to sort out a large number of rejected batches.

2. The limit of average quality after control $(A O Q L)$

It represents the maximum value of indicator $A O Q$, being the lowest level of the accepted average quality i.e.:

$$
A O Q L=\max _{0<P<1}\left(P \cdot P_{a}\right)=\max _{0<P<1}\left[\sum_{d=0}^{A} C_{n}^{d} \cdot P^{d} \cdot(1-P)^{n-d}\right] .
$$

3. Acceptable quality level $(A Q L)$

It represents the maximum percentage of inadequately solved situations or the maximum number of inadequate solutions out of one hundred situations (Number of inadequate services/100 situations) for which the batch of services is considered to be acceptable from the point of view of the average quality of production.

The $A Q L$ value (Acceptable Quality Level) is fundamental to the application of the standards of quality statistic control, providing the real basis for the acceptance of a number as 
large as possible of adequate batches and the rejection of a number as large as possible of batches inadequate from a qualitative point of view.

Reference literature as well as control standards recommend that the fixing of the value $A Q L$ should be done at the level agreed upon by the contract concluded between the partners.

If there is a great number of characteristics to be controlled and if there is a distinct $A Q L$ for each of them $\left(A Q L_{1}, A Q L_{2}, \ldots, A Q L_{n}\right)$ and distinct admissible faults respectively $\left(A_{1}, A_{2}, \ldots\right.$, $\left.A_{\mathrm{n}}\right)$ then the global $A Q L_{g}$ level is determined by means of the formula:

$$
A Q L_{g}=\sqrt[n]{A Q L_{1} \times A Q L_{2} \times \cdots \times A Q L_{n}}
$$

and

$$
A_{g}=\sqrt{A_{1}^{2}+A_{2}^{2}+\ldots+A_{n}^{2}} \quad \text { respectively. }
$$

$A Q L$ represents in the standards for quality control as well one of the invariable elements of identification of a plan of control.

4. Assessment of Average Quality for an Organizational Subdivision Belonging to a Company Providing Public Service

The company under study is a County Pension House.

County Pension Houses, still called territorial pension houses, are organized and function as descentralized public services subordinated to the National House of Pensions and Other Social Security Rights (CNPAS).

Territorial pension houses ensure throughout the territory, the unitary enforcement of the laws related to the field of state pensions and social security as well as to the field of labour accident and occupational disease insurances.

Owing to the important part county pension houses play in society, we shall further on try to determine the average quality of the department of "Management of Medical Treatment Tickets".

Under the statutes of this institution, the tasks of this department are as follows:

1. It assesses the necessary number of tickets for health resorts and submits the report to CNPAS;

2. Within the limits of the number of places alotted, it distributes tickets for medical treatment in health resorts according to the standards and criteria established by CNPAS.

3. It calculates the quota owed by the beneficiaries of the treatment tickets and draws up the order for the pay office to collect the money;

4. It assesses debits in case of miscalculation, of the quota paid by the beneficiaries of the tickets and takes steps for the money to be recovered;

5. It is responsible for the turning to good account of the tickets allotted;

6. It administers the ticket-books;

7. It collects and forwards any requests for supplementary allotment of tickets, if need be;

8. It draws up and submits to CNPAS the statistical analyses requested;

9. It ensures an extensive and updated use of Information Technology in its own activities in accordance with the strategy of CNPAS;

10. It also carries out other tasks provided for by present norms or stipulated by the deputy executive manager of the economic Department.

The results obtained by the department can be described by means of qualitative features as shown in Table 1.

The average quality can be found using several methods, namely:

1. Determining average quality at the level of existent and taken up post and at the level of the department respectively. 
This method requires knowledge of the following information: number and structure of existing and occupied posts at the level of the department; the volume of work performed within each type of post; qualitative features which describe the results obtained by each post; knowledge of the values of the qualitative characteristics which describe the results obtained at the post level.

The following items have to be calculated: the indices characterizing each quality feature separately; average quality obtained at post level; average quality at department level.

TABLE 1 .

\begin{tabular}{|c|c|c|c|c|c|c|}
\hline \multirow{2}{*}{$\mathrm{Nr}$. } & \multirow{2}{*}{ Specifications } & \multicolumn{2}{|c|}{$\begin{array}{l}\text { Medium } \\
\text { values }\end{array}$} & \multirow{2}{*}{$\begin{array}{l}\text { The calculus } \\
\text { formula for } \\
\text { the indices } \\
\text { of } \\
\text { achievement } \\
\quad R-P\end{array}$} & The value & \multirow{2}{*}{$\begin{array}{l}\text { Medium } \\
\text { quality }\end{array}$} \\
\hline & & $\mathrm{P}$ & $\mathrm{R}$ & & $\begin{array}{c}\text { of } \\
\text { achievemen } \\
t\end{array}$ & \\
\hline 1 & $\begin{array}{l}\text { Average time for drawing up and forwarding } \\
\text { of applications for tickets according to } \\
\text { STRUCTURE, RESORTS and periods of time } \\
\text { [hours] }\end{array}$ & 40 & 48 & $I=1-\frac{R-P}{P}$ & 0.8 & \\
\hline 2 & $\begin{array}{l}\text { Average time necessary to inform a customer } \\
\text { on the situation of the treatment tickets } \\
\text { available at a certain moment, according to } \\
\text { structure and allotment to resorts [hours] }\end{array}$ & 1 & 1,5 & $I=1-\frac{R-P}{P}$ & 0.5 & \\
\hline 3 & $\begin{array}{l}\text { Average time of dealing with a customer } \\
\text { from the moment of handing in the application } \\
\text { to the issuing of the treatment ticket [hours] }\end{array}$ & 30 & 35 & $I=1-\frac{R-P}{P}$ & 0.8333 & \\
\hline 4 & Average time for taking a ticket [hours] & 2 & 3 & $I=1-\frac{R-P}{P}$ & 0.5 & \\
\hline 5 & $\begin{array}{l}\text { Number of applications solved [number of } \\
\text { applications] }\end{array}$ & 1000 & $\begin{array}{c}110 \\
0\end{array}$ & $I=1-\frac{P-R}{R}$ & 1.1 & $\begin{array}{c}0.81480 \\
1\end{array}$ \\
\hline 6 & $\begin{array}{l}\text { Number of complaints lodged out of } 1.000 \\
\text { solved applications [number of applications] }\end{array}$ & 2 & 30 & $I=1-\frac{R-P}{V_{t l}}$ & 0,972 & \\
\hline 7 & $\begin{array}{l}\text { Time for solving a complaint [number of } \\
\text { complaints] }\end{array}$ & 40 & 35 & $I=1-\frac{R-P}{P}$ & 1,125 & \\
\hline 8 & $\begin{array}{l}\text { Number of complaints solved in favour of } \\
\text { customers by the department [number of } \\
\text { applications] }\end{array}$ & 1 & 15 & $I=1-\frac{R-P}{V_{t l}}$ & 0,986 & \\
\hline 9 & $\begin{array}{l}\text { Number of complaints solved in favour of } \\
\text { customers by other authorities [number of } \\
\text { applications] }\end{array}$ & 1 & 10 & $I=1-\frac{R-P}{V_{t l}}$ & 0,991 & \\
\hline
\end{tabular}

2. Assessment of average quality at the level of component activity and at department level. 
This method implies having the following information: types of activities, competence, assignments and operations carried out at department level; amount of work to be performed within each activity, competence, assignments and operations carried out at department level; the qualitative characteristics which describe the results obtained by each activity, competence, assignment and operation separately; knowledge of the values of quality characteristics.

The following items are to be calculated: indices which characterize each result obtained at department level separately; the average quality obtained by each result at department level separately; average quality obtained at department level.

3. Assessment of average quality at the level of the type of result obtained and at department level.

This method implies the knowledge of the following information: the classified list of results obtained at department level; the amount of work that has to be performed within each type of result obtained at department level; qualitative characteristics which describe each type of result obtained at department level; the values of quality characteristics.

The following are to be calculated: the indices which characterize each quality characteristic separately; the average quality obtained by each result separately; the average quality obtained at department level.

Observations: The database used for the three methods of assessment of the average quality at department level is different but the results obtained using the three methods will be approximately the same.

Example of calculation. At the level of the department: "Management of Medical Treatment Tickets" a single type of result is obtained namely: "the issuing to pensioners of treatment tickets".

The batch of services for which average quality is calculated is the issuing of medical treatment tickets to 1,000 pensioners.

From the reports provided by a department "Management of Medical Treatment Tickets" belonging to a County Pension House we have obtained the data shown in Table 1 .

For each quality characteristic the following indices will be calculated:

- the index of achievement of the value of the qualitative characteristic I is calculated as follows:

$$
I=1-\frac{R-P}{P} \quad \text { or } \quad I=1-\frac{P-R}{R}
$$

and

$$
I=1-\frac{R-P}{V_{t l}}
$$
index.

Observation. The choice of calculation is made according to the interpretation of the - the average quality achieved at the level of the department is calculated as follows:

$$
C_{m}=\sqrt[n]{\prod_{i=1}^{n} I_{i}}=0,814801
$$

\section{Conclusions}

The coefficient "average quality" having the value $C_{m}=0.814801$, it follows that at the level of the department the quality of the service provided is unsatisfactory. 
Quality is considered to be acceptable when the value of $C_{m}$ is equal to 1 or asclose to it as possible.

While carrying out its tasks, the department is quite likely to experience the occurrence of non-quality owing to the following reasons:

- the incorrect prediction of the demand for treatment tickets throughout various periods of time owing to the lack of consultation of the customers on the number, structure and their preferences;

- belated allocation of treatment tickets to County Pension Houses by CNPAS which results is discomfort for both customers and the staff of the respective pension house;

- unclear wording of the requirements for obtaining a treatment ticket;

- intercession;

- corruption;

- inadequate management of the available funds.

\section{Notations}

$$
\begin{array}{ll}
A O Q & \text { - average quality after control } \\
R & \text { - achieved value of the qualitative characteristic } \\
P & \text { - planned value of the qualitative characteristic } \\
V_{t l} & \text { - total volume of work } \\
C_{m} & \text { - average quality }
\end{array}
$$

\section{Bibliography}

1. Baron, T., (Coordinator) - Quality and Reliability, Editura Tehnică, Bucuresti, 1988

2.Drăgulănescu,M., Drăgulănescu,N., -The Management of Services Quality, Editura AGIR, Bucureşti, 2003

3. Juran, M., - The Quality of Products, Editura Tehnică, Bucureşti, 1973

4.Rusu, C., -coordinator -Manual of Economic Engineering -,,The Foundations of the Management of Quality”. Editura Dacia, Cluj-Napoca, 2002 